\title{
Ignacio Ellacuría, el hombre y el cristiano. "Bajar de la cruz al pueblo crucificado" (I)
}

\author{
Jon Sobrino, \\ Centro de Reflexión Teológica, \\ San Salvador, El Salvador
}

La figura de Ignacio Ellacuría es de una gran riqueza, y por ello puede ser analizada desde diversas perspectivas. Ellacurla fue, en electo, un gran personaje, intelectual, filósofo y teólogo, por lo que fue conocido ya desde los años setenta. Y fue también rector de la UCA, mediador y negociador en el proceso polílico salvadoreño, por lo que fue conocido sobre todo en los ochenta. Pero en la base de todo ello y a través de lodo ello estuvo y se hizo presente la persona, el hombre y el cristiano, Ignacio Ellacuría.

Aunque persona y personaje no se pueden separar adecuadamente, nos vamos a centrar en este escrito en su persona, en primer lugar, porque así nos lo han pedido, pero también porque ello nos parece sumamente útil y beneficioso por varias razones que vamos a exponer brevemente.

La primera razón es que a través del conocimiento de su persona se puede captar y apreciar mejor la obra intelectual y el impacto socio-político del personaje, lo que estimula y facilita el proseguimiento de su obra y de su causa, de todo lo cual el mundo está ahora necesitado.

Para comprender esto adecuadamente hay que aceptar, por una parte, que su persona llegó a ser y se expres 6 - en el sentido rahneriano del término- en el personaje, y es cierto también que su obra le puede sobrevivir con independencia del conocimiento que se tenga de su personal, pues como él mismo decla siguiendo a Zubiri, las acciones humanas, además de lo que tienen de opus operantis, se convierten en opus operafum, en acciones que quedan objetivadas en la historia ${ }^{2}$. Pero también es cierto que, dada la cercanía de los hechos, el conocimiento de la persona puede fungir como principio hermenéutico insustituible para comprender su pensamiento y el sentido que daba a su praxis. 
Por nnner ejemplos importantes, qué quería decir Ellacurfa con conceptos tales como realismo, mediación, revolución, Iglesia de los pobres, persecución, profecía, elc., se entiende mejor desde lo concreto de su persona, desde lo que él era en su realidad más profunda; lo cual es todavía más verdadero si se trata de conceptos-límite, tales como la utopía, el "más" en la historia, el seguimiento de Cristo, la fe en Dios... ${ }^{3}$. Aun admitiendo, pues, la necesaria circularidad y mutua referencia entre persona y personaje, creemos que para comprender a fondo el pensamiento y la praxis de Ellacuŕa es necesario, y cierlamente muy provechoso, conocer su propia vida, personal y cristiana.

$\mathrm{Y}$ a esta conclusión lleva también su forma de ser, existencial y concreta, libre y conscientemente asumida, a lo largo de su vida. A. Gonźlez ha dicho de él, trazando un paralelismo con Sócrates, que "lo característico de la labor intelectual de Ignacio Ellacuría no consiste tanto en haber puesto la praxis histórica de liberación en el centro de sus reflexiones filosoficas, sino en haber hecho de la filosofía un elemento constitutivo de una existencia dedicada a la liberación"4. Es decir, su trabajo intelectual y político en favor de la liberación son expresión, importante sin duda, pero expresión al lin de cuentas de algo más primigenio en Ellacuría, del unum necesarium diríamos: la dedicación personal a la tarea de liberar a los oprimidos.

La segunda razón para volver a su persona es evilar dos peligros: mutilar la totalidad y manipular la verdad más profunda de Ellacurfa - lo cual tiende a distanciarnos existencialmente no sólo de su persona, sino también de su causa.

Es peligroso, en efecto, concentrarse precipitadamente en su personalidad intelectual a la que se puede alabar o criticar, y a la que en cualquier caso se suele admirar por la extraordinaria profundidad de su zubirianismo térico o de su teología de la liberación. Y hablamos de peligro porque esa concentración precipitada puede acabar en reducción y puede llegar a fungir, existencialmente, como coartada sutil para no hacer nosotros - a nuestro modo y con nuestras capacidades más limitadas- lo que él hizo a través de su excepcional talento filos6fico y teologico. Se trata del conocido mecanismo de admirar para no imitar, o, en lenguaje religioso, de canonizar -santificar- para distanciar, lo cual - me temo- ocurre con frecuencia con respecto a Ellacuría.

Y es también peligroso concentrarse precipitadamente en su praxis política, pues ello suele llevar a su desfiguración y aun manipulación en favor de movimentos y procesos, del signo que fuerens, siendo así que Ellacurfa -en su análisis y praxis- se dejaba guiar sólo por si y cómo los procesos históricos aceptando la normativa ética y cristiana - favorecian a las mayorlas populares, pobres y oprimidas, y por nada más. La forma más eficaz de evitar esa manipulación es, creenıos, volver a su persona.

La tercera razón es de otra índole: es beneficioso y aun necesario recordar

Digitalizado por Biblioteca "P. Florentino Idoate, S.J."

Universidad Centroamericana José Simeón Cañas 
su persona, pues se convierte - con más facilidad que su pensamiento y praxis considerados en sí mismos- en buena nolicia, en principio humanizante para lodos.

En este mundo, en efecto, trivializado y gris, sin utopías ni ilusiones, es importante encontrar personas que, por su modo de scr, comuniquen luz y ánimo para que podamos ser humanos y cristianos. A esas personas hay que buscarlas como se busca una perla preciosa y agradecer el haberlas encontrado. Juan XXII, Monseñor Romero, el Padre Amupe han sido ese tipo de personas, y si no han tenico por qué ser "en todo perfectos", si se han mostrado "humanos", han comunicado verdad, dignidad, esperanza, amor y sentido de la vida.

Pues bien, también desde esta perspectiva hablamos de Ignacio Ellacuría, y lo juzgamos necesario, pues el mundo en que vivimos no parece tener el más mínimo interés en presentarnos y ofrecernos para nuestra humanización a personas como él y las mencionadas. Estas son buena noticia por lo que cada una de ellas, con su especificidad, comunica de luz y ánimo, y por lo que en su conjunto contribuyen a purificar el aire que respira no ya el cuerpo, sino el espírilu humano. El problema ecológico es globalizante, y por ello es también necesaria una adecuada ecología del espíritu. A construir esa ecología del espínitu colaboran personas como Ellacuría, introduciendo en el medio ambiente senticlo de la vida y de la fe.

Esos vajores personales - las raices de su persona- es lo que vamos a analizar a continuación. Lo vamos a hacer desde la doble perspectiva de lo humano y lo cristiano, notando que ambas cosas convergen en su persona, pero no en forma de simple yuxtaposición, como si formasen una unidad sólo por adición de cosas extrañas la una a la otra, sino en referencia esencial de la una a la otra, tal como él mismo entendía teóricamente esa referencia: lo cristiano, en lo que tiene de histórico, pero lambién en lo que liene de transcendente, se hisıriza y tiene que historizarse en lo humano para llegar a ser cosa real, y lo humano esı́a siempre y esencialmente abierto al "más". a lo transcendente, y encuentra su plenitud histórica -en ello consiste la fe de Ellacuría- en lo cristiano, entendido esto desde Jesús de Nazaret.

En el análisis de la persona no nos vamos a fijar en su carácter, ni en en sus cualidades y limitaciones temperamentales, que las tenía 6 . Nos vamos a fijar más bien en lo que Ellacuria ha dejado objelivamente de benéfico y liberador para los procesos del pais, de la Iglesia y de la Compañía de Jesús. En formulación que usamos con frecuencia, nos vamos a fijar en la tradición humana y cristiana, objetiva y positiva - ese surco físico cavado en la historia- que Ellacuría ayudó a generar, cuya mera existencia nos lacilita a nosotros transitar por él. En cualquier caso, esa tradición permanece como exigencia e invitación a proseguirla. 
Para terminar digamos que este escrito está basado en algunos recuerdos personales, que vamos a expresar en forma de breves reflexiones y que ilustraremos con párrafos significalivos suyos para dejar que sea el mismo Ellacuría el que lome la palabra. Dada la riqueza de su persona no ha sido fácil la selección del material, y en ello nos hemos dejado guiar por lo que nos parece ser de mayor utilidad en el mundo actual. Y digamos también que los recuerdos sobre los que se basan estas reflexiones provienen de los dieciséis años que conviví con él. Y como esos años —de 1974 a 1989 — fueron de suma densidad histórica y como su modo de ser no era dado en absoluto al fingimiento, creo poder decir que lo llegué a conocer bien y en las cosas más profundas de su persona.

\section{Primera parte: el hombre}

\section{Bajar de la cruz al pueblo crucificado}

Si algo me llamó poderosamente la atención en Ellacuría desde el principio fue su pasión por el servicio. Su pregunta fundamental, transcendental diríamos, lue siempre la de "qué tengo que hacer", mediación histórica del "buscar siempre la voluntad de Dios y cumplirla", tan típicamente ignaciana. Su pregunta en el hacer cotidiano, categorial dirlamos, para no desviarse ni desvirtuar lo que tenía que hacer, era también la de san Ignacio: "a dónde voy y a qué". Y la esencia de ese hacer fue, por último, servir, esencial también al ideal ignaciano de "en todo amar y servir".

En mi opinión, ahí está lo fundamental de su vida y de su vocación como jesuita, pero más hondamente todavía como humano: saberse llamado a un servicio, poner todas sus cualidades - y yo añadiría, incluso sus defectos- para llevarlo a cabo de la mejor manera posible y mantenerse fiel a ello hasta el final7. Sin ninguna rétorica y dicho con rigor, su vida fue una vida des-centrada, un servicio en favor de otros, y, cada vez más, un servicio también desde los otros, tanto porque esos otros daban sentido a su vida como porque lo iluminaban sobre cómo servir.

Y no sólo dedicó su vida a servir, sino que a lo largo de toda ella fue preguntándose qué significaba en concreto ese servicio al que se sabía llamado, y paulatinamente llegó a comprenderlo no como cualquier servicio, sino como un servicio especílico: bajar de la cruz al pueblo crucificado. Esto es lo que queremos analizar a continuación.

\subsection{La raíz de todo: el sufrimiento de las víctimas}

Ellacuría no fue sensiblero en absoluto, pero su vida esluvo transida de misericordia, entendida ésta de forma muy concreta: (a) como (re)acción, no pues formalmente como puro sentimiento, (b) hacia el sufrimiento de las víctimas sobre todo históricas, (c) benéfica para éstas y liberadora en contra de sus 
victimarios, (d) historizada según fuese la víctima y su sufrimento, y (e) todo ello por el mero hecho de que existe el tal sufrimiento8. Esa misericordia, como acabamos de decir, debe ser historizada, y Ellacuría la historizó fundamentalmente en forma de justicia, tanto por la masividad del herido en el camino pueblos enteros, millones de seres humanos, "deshechos y pilurafas", como él decía- como porque la razón de las heridas está en la injusticia, en la injusticia estructural sobre todo.

En lo que queremos insistir, sin embargo, es en que el origen de todo ello no está ni en un descarnado imperativo categórico ni en el atractivo estélico de poner en práctica una teoría de la justicia. El origen está en que a Ellacuría se le removieron las entrañas al ver a todo un pueblo postrado, oprimido, engañado, burlado -en el lenguaje vigoroso que solía usar. Ante eso reacciono, no se quedó en el puro lamento y nunca pactó con ese dolor, a lo que tiende hoy aun cuando se hiciese con buena conciencia- el posımodernismo por aquello de que hay que aceplar el fraginento o el neoliberalismo por aquello de que no hay otra solución.

En este sentido y por esa razón quisiera decir desde el principio que Ellacuría fue y permaneció hasta el final un radical. El sufrimiento de las víctimas tenía profundas raíces, y esas raíces, no cualquier cosa, es lo que tenía que ser erradicado y sustituido por otras que produjesen vida y fraternidad. Por ello y hasta el linal de sus días se reveló contra algo que está hoy muy vigente y que se puede llamar "la geocultura de la desesperanza y la teología de la inevitablidad"9. Y así, en su último discurso en Barcelona, el 6 de noviembre de 1989, verdadero testamento, dijo las siguientes palabras:

Desde esta perspectiva universal y solidaria de las mayorfas populares, el problema de un nuevo proyecto histórico que se va apuntando desde la negación profética y desde la afirmación utópica apunta hacia un proceso de cambio revolucionario, consistente en revertir el signo principal que configura la civilización mundial 10.

Hablar de revolución, es decir, de Iransformaciones radicales, y de revertir la historia, es decir, de operar un giro de 180 grados sobre ella, no es nada frecuente en estos días. Por ello - para poder captar en verdad quién fue Ignacio Ellacuría- comenzamos nuestra reflexión con estas palabras que bien pudieran servir de conclusión final, y lo hacemos para insistir en que lo que formuló con gran vigor al final de su vida es lo que dio sentido a toda ella: revertir una historia de inhumanidad.

Esta radicalidad no significa en modo alguno ligereza juvenil o irresponsabilidad de alguien que fuera mero académico, sino que era fruto de su seriedad personal en relación a la realidad. Por ello Ellacuría exigía al intelectual, y análogamente a todos, las siguientes cuatro cosas $-\mathrm{y}$ cito de memoria. Objetividad

Digitalizado por Biblioteca "P. Florentino Idoate, S.J."

Universidad Centroamericana José Simeón Cañas 
para acercarse a la realidad, captarla y analizarla tal cual es --de lo cual, por cierto, se desprende la opción por los pobres como exigencia objetiva de la realidad. Realismo para dar los pasos que sean ajustados a la realidad y por ello posibles, pero entendidos éstos como pasos, es decir. como aquello que por definición debe ser alcanzado y sobrepasado para llegar a lo que realmente se pretende y que nunca debe ser perdido de vista. Profecía para denunciar los males de la realidad - sin acomodarse a ella-, y hacerlo categóricamente porque la maldad se muestra con ultimidad. Utopía, por último, para proponer aquello a lo que apunta la negación de los males, y, más allá de ello, el horizonte de plenificación personal y social.

En mantener la necesidad de estas cualro cosas y de simultanearlas consiste, en mi opinión, la genialidad de Ellacuría, pero - y en ello hay que insistir- lo que ponía en movimiento, lo que otorgaba dinamismo y lo que daba dirección a cada una de ellas, y lo que movía existencialmente a la difícil combinación de todas ellas, era el dolor que le causaba el sufrimiento de las víctimas, sufrimiento que nunca relativizó ni con el que nunca pactó. Eso fue fundamental y fundante en la vida de Ellacuría. Veámoslo.

Ante todo Ellacuría se acercó y buscó siempre ver la realidad, cosa nada obvia en quienes socialmente pertenecen a clases medias, en quienes profesionalmente trabajan en una universidad y en quienes tienen responsabilidad institucional en la Iglesia y en la vida religiosa II. Y lo que vio fue la verdadera realidad, es decir, la realidad tal cual es, máximo interés, por otra parte, del Ellacuŕa filosofo. Afectado primigeniamente por esa realidad verdadera, la formulo de muchas y variadas formas, pero la aprehendio ante todo como inhumana pobreza, como muerte cruel e injusta de las mayorías. Ast lo afirmó en lenguaje cristiano con inigualable vigor $-y$ para nosotros también con inigualable rigor- para comunicar la radicalidad y ultimidad de cómo veía él y juzgaba la realidad.

Entre tantos signos como siempre se dan, unos llamativos y otros apenas perceptibles, hay en cada tiempo uno que es el principal, a cuya luz deben discernirse e interpretarse todos los demás. Ese signo es siempre el pueblo historicamente crucificado, que junta a su permanencia la siempre distinta forma histórica de su crucifixión. Ese pueblo crucificado es la continuación histórica del siervo de Yahvé, al que el pecado del mundo sigue quitándole toda figura humana, al que los poderes de ese mundo siguen despojando de todo, le siguen arrebatando hasta la vida, sobre todo la vida 12.

Esta conceptualización teológica de la realidad - llamar a los pobres de este mundo siervo sufriente de Yahvé o equipararlos a Cristo crucificado- muestra el vigor y talante del Ellacuría teólogo, pero muesira también su captación de la tragedia de la realidad: la muerte, el terrible dolor de las víctimas de este mundo. Así vefa Ellacuría la verdadera realidad de nuestro mundo. Al conceptua-

Digitalizado por Biblioteca "P. Florentino Idoate, S.J."

Universidad Centroamericana José Simeón Cañas 
lizarlo en lenguaje cristiano, eleva la realidad a concepto teológico, pero antes que nada vierte sobre nuestro mundo un juicio radical, nada postmoderno y ni siquiera s6́lo guiado por la modernidad: este mundo es pecado, radical negatividad, radical negación de la voluntad de Dios y manifestación máxima del rechazo de Dios. Este mundo es la aparición histórica del siervo de Yahvé en cuanto siervo sufriente y la aparición de Cristo en cuanto crucificado.

Y también desde la filosofía, al proponer el carácter desideologizante y desencubridor de la realidad encubierta que debe tener aquélla, reclama a Heidegger que "quizás en vez de preguntarse por qué hay más bien ente que nada, debería haberse preguntado por que hay nada - no ser, no realidad, no verdad, etc. - en vez de ente"13. El primer impacto, pues, que causa la realidad es el de radical negatividad.

Se podrá compartir o no el análisis teológico y filosófico de Ellacurfa, pero de lo que no se puede dudar es del impacto que le causo la tragedia de este mundo. En lenguaje castizo y con talante profético dijo en 1989, a proposito del quinto centenario, que lo ocurrido hace cinco siglos no fue descubrimiento sino encubrimiento, y añadió en formulación histórico-teológica, que al pueblo latinoamericano, españoles y portugueses antes, norteamericanos ahora, "lo han dejado como a un Cristo"14.

\subsection{La pasión por la justicia}

Cuando poco después de su muerte se quiso honrar cristianamente a todos los mátitires de la UCA se pensó en atribuir a cada uno de ellos la bienaventuranza - ya que eran ocho- que mejor les cuadrara. Pues bien, a Ellacurfa, sin excepción, le adjudicaron la que dice "dichosos los que tienen hambre y sed de justicia". La elección fue certera.

Por responder a su sentido innato de rectitud y quizás también a su temperamento luchador y retador, la justicia le obsesionó a Ellacuría. No se trataba para él sólo de eliminar o aliviar la pobreza, sino de cambiar realmente un mundo antagónico, dividido entre empobrecidos y empobrecedores, entre víctimas y verdugos, un mundo que expresa el mayor fracaso de lo humano, la propia autodestrucción de la Tamilia humana, y el mayor fracaso del Dios creador ${ }^{3}$. Por ello, no en vano ni a la ligera formulaba la realidad de los pobres como la de "pueblos crucificados", para expresar con ello que se trata de pueblos enteros que mueren, pero que, además, son dados muerte injustamente por otros seres humanos.

Teniendo ante los ojos a este mundo real, Ellacurfa apoy6 toda accion buena que aliviase el sufrimiento humano, por supuesto, pero el dolor y la muerte de millones de víctimas a manos de unos pocos lo movió a privilegiar no cualquier acción, aunque fuese buena, sino la misericordia y el amor especificos que se PERTENECE A:

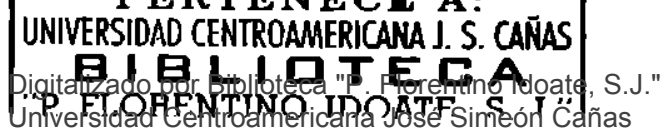


dirigen a las mayorías en cuanto oprimidas, es decir, la justicia. Este amor eficaz a las mayorías y no un espíritu elitista o de superioridad - las grandes cosas que quería hacer y el relacionarse cuando era necesario con los que están arriba en la historia- es lo que dirigió la elección de lo que tenfa que hacer.

Asf, la primacía que daba a la justicia lo llevó a propiciar el tipo de praxis que tuviesc mayor incidencia en las estructuras. Apoyaba también obras y actividades en contacto inmediato con los pobres, pero de entre ellas privilegiaba las que tuviesen un potencial de incidencia importante para las mayorfas - de ahí su admiración y apoyo, además del cariño, a Rutilio Grande y al equipo en Aguilares. Y ése fue su modo personal de historizar las conocidas palabras de san Ignacio, "el bien, cuanto más universal, es más divino".

También insistió en la relación dialéclica, excluyente y duélica, entre la justicia y la injusticia. Por ello, ya al linal de los años sesenta, y aun antes de que se popularizara en Centroámerica lo que se estaba gestando en Brasil y en el cono sur, expresó la necesidad no sólo de desarrollo sino, formalmente, de liberación, correlato de la opresión, para que la justicia pudiera llegar a ser realidad. En términos existenciales, y para expresar la relación duélica entre justicia e injusticia, mencionó desde muy pronto la necesaria disponibilidad a la persecución en la lucha contra la injusticia. Y de esta relación duélica dedujo también la diferencia y oposición entre los dioses que propician una u otra: el Dios de vida y los ídolos de muerte 16.

Por último, Ellacuría vio en la justicia una realidad central - no la única一 para comprender y construir el contenido fundamental de su leología: el reino de Dios, reino de vida básica y digna para los pobres, y —erradicada la opresión y la represión- reino de fraternidad para todos, tal como lo anunciaron los profetas del Antiguo Testamento y Jesús de Nazaret, y tal como lo analiza hoy la teología de la liberación:

Lo mismo que Jesús vino a anunciar y realizar, esto es, el reino de Dios, es lo que debe constituirse en el objeto unificador de toda la teología cristiana, así como de la moral y de la pastoral cristianas: la mayor realización posible del reino de Dios en la historia es lo que deben proseguir los verdaderos seguidores de Jesús ${ }^{17}$.

\subsection{La nniversidad al servicio de la liberación}

Ellacuría fue, ciertamente, un excepcional luchador y teórico de la justicia, pero a mi entender no estuvo en esto lo más original y creativo suyo, sino en las siguientes dos cosas. La primera fue concebir cualquier realidad personal e institucional desde su potencial en favor de la justicia. $Y$ la segunda fue dar ultimidad al sufrimiento de las víctimas y mantener siempre presente su interpelación en los procesos de liberación, prolongados y cambiantes, para, desde 
ese sufrimiento, buscar los caminos más adecuados de solución. Esto es lo que queremos mostrar en éste y en el siguiente apartado en dos importante ejemplos: su teoría de la universidad y su acompañamiento al proceso salvadoreño. Veamos ahora lo primero.

Para Ellacuría todos, personas e instituciones, deben ponerse al servicio de la justicia, pero en el tercer mundo y ciertamente en El Salvador ésta pasa historicamente por la liberación ${ }^{18}$. Esto quiere decir que para el Ellacurla -que era universitario de profesión- esla exigencia genérica se le concretó existencialmente en cómo la universidad puede autocomprenderse desde la liberación y ponerse a su servicio19.

Cómo juntar universidad y liberación no es nada evidente, y la historia muestra que la universidad ni siquiera teóricamente ha sido pensada desde y para la justicia y la liberación. Pero aunque se aceptase teóricamente la relación esencial entre ambas cosas, queda siempre el difícil problema de pensar cómo poner al servicio de la liberación lo especílico de la universidad, de modo que ésta pueda servir a aquélla como universidad, sin que ese servicio la violente ni la desnaturalice. La larea para Ellacuría consistió, entonces, en buscar un modo de hacer convergir universidad y liberación, a lo que añadió la necesidad de repensar la dimensión polírica de la universidad, evidente en una explosiva situación histórica, y -ya que era jesuita y en cuanto tal se le había encomendado una misión universitaria - su inspiración cristiana. Veamos lo fundamental de su reflexión.

a) Ellacuría insistió en que lo que se tenía que poner al servicio de la liberación de las mayorías populares era una universidad y no otra cosa, es decir, una institución a la que le es esencial el cultivo del saber racional y, también, de alguna forma, el cultivo de la cultura. Por ello insistía en la necesidad de generar saberes, de llegar a conocer - a través de la investigacion - la realidad, sus dinamismos positivos, sus problemas, y sobre todo las causas y soluciones. Todo ello debía ser comunicado en la docencia, de modo que lo que se debía enseñar, a través de cualquiera de las materias y en todas ellas, era la realidad nacional. Y solía decir también que "otras universidades nos podrán ganar en otros conocimientos, pero sobre la realidad del pals nadie debe saber más que la UCA".

También estaba convencido de que una universidad —dejándola ser universidad- podía ser beneficiosa para la liberación, pues la razón —como razón leórica y práctica, profética y utópica-es útil y muchas veces insustituible para alcanzar la verdad que debe dirigir los procesos de liberacion. Entre universidad -que ejercita la razón-y proceso de liberación —exigido por la realidad- no sólo no hay oposición, sino que hay convergencia.

b) De dónde le viniera esa convicción es cosa a analizar, pero en cualquier caso fue muy honda20. Quizás le viniera de la experiencia personal de que la 
caso fue muy honda20. Quizás le viniera de la experiencia personal de que la verdad siempre es iluminadora y vivificadora, aunque también nos puede sumir en dudas y cuestionamientos. Pero en mi opinión, la convicción le provino de verificar cómo con la razón se establece la verdad de la realidad y se apunta a los caminos de solución, con lo cual los procesos concretos de liberación están basados sobre roca firme; y cómo, a la inversa. sin la razón, dejándose llevar sólo del entusiasmo y del buen corazón o de prejuicios dogmálicos en asunios lan serios, se cometen graves errores. Esto se le relorzo con la constatación histórica de que son los poderosos y opresores los que oprimen la razón y solocan la verdad, mientras que son los pobres y oprimidos los que no le temen a la razón ni a la verdad, y esperan más bien que ésla sea proclamada y la consideran en su favor.

La posiblidad de lo primero ya quedo denunciada por Pablo - "¡ay de los que oprimen la verdad con la injusticia!"-, con la total deshumanización que acompaña al hecho primigenio de oprimir la verdad - todo lo cual era realidad generalizada en el país en que prolileraba la mentira inslitucionalizada y la consiguiente deshumanización. Lo segundo, más impensuble a priori, fue también experiencia generalizada. Cuando Monseñor Romero decía la verdad, los pobres se alegraban - aun cuando ellos fueran también crilicados- porque sentían que la verdad los defendía.

Ellacuría pudo, pues, constatar que los mismos que oprimían la verdad oprimían a los pobres, y que los mismos que esperaban la liberación de la opresión eran los que esperaban la liberación de la verdad. Aun antes, pucs, de pensar cómo en concreto poner la universidad al servicio de la liberación, Ellacuría intuyó sus inmensas posibilidades, que aumentan — pensaba él y lo defendíasi la universidad se mantiene como tal. En ese sentido, vio convergencia y aun afinidad entre la realidad específica de una universidad y los procesos de liberación. Vio convergencia entre ambas, porque la verdad que busca y encuentra la razón es en sí misma históricamente liberadora. Y vioafinidad porque en ambos casos hay que pasar por un proceso de liberación, pues la consecución de la verdad supone también un proceso de pasar no sólo de la ignorancia al conocimiento, sino de la mentira a la verdad, de la verdad oprimida a la verdad liberada2l.

c) Buscar y encontrar la verdad a través de la razón, y proclamarla a través de la palabra es un quehacer específicamente universitario, que, además, pone a la universidad en situación de poder reconocer la realidad como realidad de pobres, y en situación de hacer, éticamente, una opción por ellos. Esto es lo que según Ellacuría se deriva del reclo ejercicio de la razón en la universidad.

Pero además, Ellacuría insistió novedosamente en la realidad de la universidad como fuerza social y en la responsabilidad que de ahí se deriva: 
ricamente por lo que es la sociedad en la que vive y destinada a iluminar y transformar, como fuerza social que es, esa realidad en la que vive, de la que vive y para la que debe vivir. De ahr surge la cuestión fundamental. ¿En qué consiste el servir universitariamente a la iluminación transformadora de la realidad social, de la sociedad y del pueblo, en que está inserta?22.

Ante esta exigencia de la realidad, Ellacuría recalcó, en primer lugar, que hay que darle una respuesta, y que esa respuesta la puede y debe dar la universidad como un lodo: con la verdad racional y con la acumulación de saberes verdaderos, la universidad puede proyectarse hacia fuera y convertirse en conciencia crílica y constructiva, profética y utópica de la sociedad, puede inhuir en la conciencia colectiva y en los movimientos y grupos que dirigen procesos liberadores, y todo ello para configurar una sociedad justa. A esta tarea, que introdujo pioneramente en la leoría de universidad es, a lo que llamó proyección social.

d) Por último, Ellacuría vio en una universidad así concebida la posibilidad de reformular lo que debe ser su dimensión política y su inspiración cristiana. Ya hemos dicho que, dada la convulsa situación del país, era inevitable preguntarse cómo la universidad iba a incidir políticamente. $Y$ dado que la universidad estaba bajo la dirccción de jesuitas - más la convicción del potencial liberador de la fe cristiana- cra también inevitable preguntarse cómo y en qué sentido iba a ser cristiana. Ambas cosas - dimensión política e inspiración cristianason en sí mismas difíciles de teorizar y de manejar; y no sólo eso, sino que las universidades son proclives a pretender haber encontrado soluciones - fáciles y a la postre falsas- al problema. Ante esto, Ellacurla desarrolló una nueva teoría de la dimensión política y de la inspiración cristiana de la universidad, pero antes desenmascaró una falacia generalizada: pensar que lo político y lo cristiano llegan a ser realidades también universitarias por el mero hecho de que se llevan a cabo en la universidad.

Dicho en [orma gráfica, no es infrecuente concebir como actividad universitaria un milin o un acto religioso porque han sido celebrados en la universidad, con lo cual la universidad puede pensar que está cumpliendo su misión política y cristiana cuando en ella, física y geográlicamente, se llevan a cabo, por ejemplo, actividades de partidos políticos o de grupos revolucionarios, o cuando en ello se celebran liturgias cristianas.

No está ahora en discusión que ambas cosas, actividades políticas y religiosas, son o puedan ser buenas, ni que no puedan llevarse a cabo en el campus universitario. Lo que cuestionaba Ellacurla es pensar que ésa sería la manera correcta de relacionar la universidad con la política y con lo cristiano, y de cumplir así adecuadamente con esa doble responsabilidad. El pensaba, más bien, que esa relación no podía estar basada en el presupuesto simplista de que lo que ocurre espacialmente en la universidad -en un ubi categorial- es ya universi-

Digitalizado por Biblioteca "P. Florentino Idoate, S.J."

Universidad Centroamericana José Simeón Cañas 
tario, sino que esa relación tiene que estar basada en lo que sea la realidad especílica de la universidad -un quid sustancial.

e) La adecuada conjunción entre universidad y política se dará, entonces, cuando la dimensión polf́tica se desprenda de las inismas funciones específicamente universilarias. Por eso, Ellacuría afirmaba polémicamente que

si toda acción universitaria pública es de algún modo o de otro, en una medida o en otra, una acción política, no toda acción política emprendida materialmente en la universidad o por los universitarios es una acción universitaria23.

La solución estará, entonces, en concebir la política en relación a lo especfficamente universitario:

Una universidad clabora univcrsilariamente su politicidad fundamental, cuando entre sus diversas funciones -docencia, investigación y proyección social- da el máximo rango directivo a la proyección social de modo que ésıa determina últimamente a las otras, aunque también sea ordenada por ellas. Desde luego que no se trata de una proyección social cualquiera, sino de aquella que busca prioritariamente la radical transformación del desorden establecido de la injusticia estructural24.

f) Este mismo enfoque sirve para comprender en qué consiste la inspiración cristiana de la universidad. Qué sea ésıa no se decide en lo que se haga de explícitamente religioso en la universidad (liturgias, educación cristiana, cuidado de la ortodoxia), cosas buenas, pero que pueden hacerse de hecho y de derecho fuera de la universidad, sino en cómo están transidas de cristianismo las funciones fundamentales de la universidad, investigación, docencia y proyección social. Esto - según la teología de la liberación y la de Ellacuría- es posible en la medida en que la universidad como un todo ponga todo su peso social al servicio de la construcción del reino de Dios, llevado a cabo desde la opción preferencial por los pobres, y en este sentido y dicho sin ninguna retórica Ellacuría trató de historizar desde la universidad la misma misión que Monscñor Romero llevó a cabo desde su plataforma pastoral.

Sobre estas dos cosas, la misión de la universidad de construir el reino de Dios y hacerlo desde la opción preferencial por los pobres, Ellacuráa escribí abundantemente. Reproducimos ahora sólo dos párrafos de un famoso discurso que pronuncí cuando la Universidad de Santa Clara le otorgó, en 1982, un doctorado honoris causa. Sobre la construcción del reino de Dios dijo lo siguiente en palabras programáticas:

... el deseo de que el reino de Dios se haga cada día más presente entre los hombres... Inmersos en esa realidad (del tercer mundo), poseídos por clla, nos preguntamos qué hacer universitariamante. $Y$ respondemos, ante todo, desde un planteamiento ético: transformaria, hacer lo posible para que Digitalizado por Biblioteca "P. Florentino Idoate, S.J."

Universidad Centroamericana José Simeón Cañas 
el bien domine sobre el mal, la libertad sobre la opresión, la justicia sobre la injusticia, la verdad sobre la falsedad, el amor sobre el odio. Sin este compromiso y sin esta decisión no comprendemos la validez de la Universidad y, menos aún, la validez de una universidad de inspiración cristiana25.

Y por lo que toca a la opción por los pobres. Ellacuría la formuló ese día parafrasenado las conocidas palabras de Monseñor Romero: "Estas homilfas quieren ser la voz de este pueblo. Quieren ser la voz de los que no tienen voz"26. Eso mismo es lo que Ellacuria pensaba que tenía que ser la universidad.

Una universidad de inspiración cristiana es aquella que enfoca toda su actividad universitaria ... desde el horizonte iluminador de lo que significa una opción preferencial cristiana por los pobres ... La universidad debe encarnarse entre los pobres intelectualmente para ser ciencia de los que no tienen voz, el respaldo intelectual de los que en su realidad misma tienen la verdad y la razón, aunque sea a veces a modo de despojo, pero que no cuentan con las razones académicas que justifiquen y legitimen su verdad y su razón 27.

\subsection{La justeza de la praxis y la interpelación permanente}

a) Ellacuria fue un apasionado de la justicia, y por ello profeta y utópico, pero por la misma razón estuvo también obsesionado por la justeza, es decir, por ajustarse a la realidad y a sus posibilidades reales. Esto no lo convirtió en oportunista, ni en puramente pragmático o posibilista, cosa que ni su temperamento, ni su amor a las mayorías, ni su fe cristiana se lo facilitaba, y cosa que hay que aclarar, pues algunos últimamente nos lo quisieran presentar así. Y es que una cosa es analizar y actuar sobre la realidad para que ésta dé de sí lo más posible, teniendo y manteniendo un claro horizonte - ulópico- al que se quiere llegar, evaluando siempre desde ese horizonte lo logrado, y oura cosa es la aceptación, entre resignada y desresponsabilizada, de lo que se puede y no se puede hacer.

La primera actitud es buscadora activa de soluciones y comprende los "pasos" posibles como aquello que se puede alcanzar, pero también, como hemos dicho, como aquello por lo que hay que pasar para sobrepasar la situación existente y apuntar a un horizonte utópico. La segunda puede degenerar en el "así son las cosas", con lo que esto conlleva de tendencia a la inacción y, sobre todo, a privilegiar muy realmente a los pocos para quienes las cosas que así son son muy buenas y de abandonar a los muchos para quienes esas mismas cosas son muy malas.

Según esto, no nos parece muy acertado describir a Ellacuría fundamentalmente como realista o posibilista -aunque las palabras sean lo de menos-, sino como activo buscador de caminos y de soluciones reales ajustados a la realidad, pero siempre en el horizonte utópico que la misma realidad exige. $Y$ en 
esto sí fue insigne. Podrá discutirse si acertó o no siempre, pero nos parece que está fuera de discusión (a) que siempre buscó caminos activa y creativamente, adelántandose a los que otros proponían, (b) que, aunque conoció e hizo uso de teorías políticas, no siguió mecánicamente ninguna receta, y (c) que en ello mantuvo su propio criterio sin importar le los ataques de la derecha y sin actuar para conseguir el aplauso de la izquierda.

b) Ejemplos de esto fueron sus abundantes pláticas con personas e instituciones, políticos, sindicalistas, diplomáticos, comandantes y combatientes del FMLN, obispos, nuncios, sacerdotes y religiosas, mujeres de los comités de madres de desaparecidos, organizaciones no gubernamentales, Cristiani en los últimos meses, y un muy largo etcétera. La linalidad de esta desaforada actividad no era otra que animar a que todas estas personas e instituciones contribuyesen objetivamente a dar pasos positivos en el proceso o. al menos - y en eso sí sc le puede llamar realista a Ellacuría - conseguir "ablandar" a los más retrógrados entre los gobernantes, políticos, oligarcas y militares, para racionalizar al máximo el poder de que gozaban o para reducir al mínimo su irracionalidad.

Y ejemplo de ello fue también su continua apertura, pensada, sopesada y contrastada siempre con las exigencias y posiblidades de la realidad, a cambiar, Iransitar y animar a otros a transitar - "líder es el que va delante", solía decirlos caminos que inás se ajustaban a la realidad, aunque ello lo llevara a abandonar viejos caminos conocidos y a enrumbarse hacia otros nuevos y desconocidos.

Así, en los comienzos de los setenta apoyó los inicios de pláticas sobre reforma agraria y apoyó, en contra de la izquierda, el límido intento de la reforma del presidente Molina, a quien después criticó en uno de sus más brillantes y proféticos editoriales "A sus órdenes mi capital" - lo que a su vez costo la explosión de una poderosa homba en la UCA.

También en los setenta, 1972 y 1977, siguió muy atentamente las elecciones, cuyas posiblidades y límites analizó de antemano, y a las que denunció después por fraudulentas. También en esos años delendió en principio y en muchas de sus actividades a los movimientos populares, a los que siempre apoyó en su fundamental justicia, a los que siempre defendió cuando sus derechos más elementales eran violados y a los que también criticó por sus errores y reduccionismo.

En 1979 apoy6 - como lo hizo también Monseñor Romero- el incruento golpe de Estado del 15 de octubre, enfrentándose a la izquierda, que no dio prácticamente ninguna oportunidad a la junta de gobierno, y denunciando después a la Fuerza Armada y a la democracia cristiana por haber prostituido las inejores intenciones que estaban tras el golpe. 
A finales de 1980, en medio ya de una abierta barbarie y en los preámbulos de la guerra que iba a desencadenar el FMLN - con la mayor objetividad posible, y con temor y temblor, lo recuerdo bien- llegó a la conclusión de que la situación era tal que la solución sólo podía ser político-militar.

En febrero de 1981, s6́lo un mes después de la fallida ofensiva final, en Managua, donde estaba exilado, dijo que la guerra no la iba a ganar nadie y que la solución estaba en la negociación. No le atrajo esto muchas simpatías entonces; no de la derecha por supuesto - “ ¿cómo negociar con criminales?"-, pero tampoco de la izquierda. Ellacuría, sin embargo, siguió proponiendo este camino y buscando el apoyo de la tercera fuerza, mal entendida por la izquierda, y trabajando por ello hasta el final.

c) Como hemos dicho antes, se podrá estar de acuerdo o no con lo concreto de los análisis políticos de Ellacuría, y expertos habrá que analicen la justeza de sus opciones. Si lo hemos recordado, sin embargo, es para recalcar algo imporlante de su persona: ante la tragedia de las mayorías hay que dejar toda comodidad -de cuerpo y alma - a la que son proclives académicos y eclesiásticos, escudándose en aparentes buenas razones, y hay que desvivirse para buscar una solución. Y para estar en lo correcto, o al menos en la dirección de la solución, hay que abandonar todo dogmatismo a priori y mirar ante todo cómo les va a las mayorías populares - y no en directo al gobierno, al FMLN, al manual de la revolución o a la embajada norteamericana-, según aquello de Monseñor Romero de que "la Iglesia apoyará uno u otro proceso político según le vaya al pueblo".

Por qué Ellacuría, tan firmemente estructurado en su modo de pensar y nada dado a veleidades irresponsables, cambiase y buscase nuevos caminos de solución, y por qué lo hizo muchas veces "en solitario", pucde deberse, en parte, a su temperamento desafiante e incluso a veces prepotente. Pero sería un error buscar la explicación de esa continua voluntad de búsqueda en lo meramente temperamental suyo. Esla hay que buscarla -es mi convicción- en lo más hondo de su persona, quien, al preguntarse como ser humano qué hacer por el país, se estaba preguntando a la vez qué hacer consigo mismo en este mundo de injusticia.

A ese nivel personal, Ellacuría escuchó el clamor de los pobres y respondió lo más ajustadamente que supo. Pero esta respuesta tuvo un proceso -en lo cual hay que insistir, pues pocos son los que se arriesgan a cambiar en estas cosas. De su duración - unos veinte años-, de su complejidad - necesidad de tener en cuenta cada vez más factores- y de sus costos - trabajos, persecución. soledad muchas veces, muerte al final- puede colegirse qué hondos niveles de su persona tocaron los clamores de los pobres.

En Valladolid, en 1982, de nuevo en tiempo de exilio, Ellacurfa pronunció 
una conferencia que terminó con unas palabras, que, aun cuando él no era dado a hablar de sf mismo en este tipo de lenguaje, bien pueden interpretarse como autobiográficas, es decir, sobre cómo le afectó a él vivir en medio de un mundo de víctimas.

Lo único que quisiera - porque eso de interpelación suena muy fuerteson dos cosas: que pusieran ustedes sus ojos y su corazón en esos pueblos que están sufriendo tanto -unos de miseria y hambre, otros de opresión y represión- y después (ya que soy jesuita), que ante ese pueblo crucificado hicieran el coloquio de san Ignacio en la primera semana de los Ejercicios 28 , preguntándose: ¿qué he hecho yo para crucificarlo?, ¿qué hago para que lo descrucifiquen?, ¿qué debo hacer para que ese pueblo resucite?29.

Visto en retrospectiva, pensando en el Ellacuría teórico, rahneriano y zubiriano, conocedor y apreciador de algunos aportes del marxismo, buscador incansable de racionalidad, creo que la única verdad histórica que realmente fue para él inamovible en sus muchos años de camino, su único "dogma" existencial, por así decirlo, fue la realidad del pueblo crucificado y la exigencia a bajarlo de la cruz.

\section{La inteligencia al servicio de la justicia}

Este buen samaritano y hombre de justicia, que fue Ignacio Ellacuria, ejercio la misericordia sobre todo a través del uso de la inteligencia, a lo cual ya hemos aludido. Pero queremos detenernos un poco en ello para ahondar en y comprender la ulimidad de su misericordia, y -aunque esto no sea ahora lo central de nuestro tema - para que cualquiera que se piense a sI mismo "profesional de la inteligencia," sobre lodo con aires postmodernos, vea cómo ésta puede y debe ponerse al servicio de la realidad, de la justicia y de la liberación. En otras palabras, queremos ver cómo lo que se expresó en el intelectual Ellacuria fue su persona dedicada a una causa que tenfa prioridad lógica sobre el mero hacer avanzar el conocimiento, y cómo ello puede ayudar a otros pensadores, academicos y científicos, a ser - como solemos decir- filosófos de la liberación. ingenieros, médicos, econornistas de la liberación, abogados, historiadores, literatos de la liberación...

\subsection{La dimensión noética, ética y práxica de la inteligencia}

Ya hemos dicho que para el mismo Ellacuría y desde una perspectiva existencial lo más decisivo suyo no fue simplemente el ejecicio de su inteligencia - prodigiosa en verdad-. sino dedicarse $-y$ dedicarla - al servicio de la liberación. Pero esta dedicación a la liberación, dimensión que debe estar presente en todos los niveles de la persona, la introdujo en la comprensión de lo que es el ejercicio de la inteligencia, cuya estructura formal definió como "aprehender la realidad y enfrentarse con ella" 30 .

Digitalizado por Biblioteca "P. Florentino Idoate, S.J."

Universidad Centroamericana José Simeón Cañas 
Ellacuría analiź cómo y en qué formas ocurre ese enfrentamiento, y concluye que ocurre al nivel noético, con el presupuesto de estar encarnados en la realidad, al nivel ético, con el presupuesto de que la inteligencia es interpelada por la realidad y debe responder a la exigencia de la interpelación, y a un nivel práxico, tomando a su cargo un quehacer real. Esto es lo que él mismo dice en las sigientes palabras, precisas y densas, que se han convertido en un texto clásico:

Este enfrentarse con las cosas reales en tanlo que reales tiene una triple dimension: el hacerse cargo de la realidad, lo cual supone un estar en la realidad de las cosas - y no meramente un estar ante la idea de las cosas o en el sentido de ellas-, un estar "real" en la realidad de las cosas, que en su carácter activo de estar siendo es todo lo contrario de un estar cósico e inerte e implica un estar entre ellas a través de sus mediaciones matcriales y activas; el cargar con la realidad, expresión que señala el fundamental carácter ético de la inteligencia, que no se le ha dado al hombre para evadirse de sus compromisos reales sino para cargar sobre sí con lo que son realmente las cosas y con lo que realmente exigen; el encargarse de la realidad, expresión que señala el carácter práxico de la inteligencia, que sólo cumple con lo que es, incluso en su carácter de conocedora de la realidad y comprensora de su sentido, cuanto toma a su cargo un hacer real31.

Según esto, la finalidad última de la teología no consiste adecuadamente sólo en hacer avanzar el conocimiento - aunque esto sea bueno y necesario para dicha finalidad-, sino en encargarse, de la manera más adecuada posible, de la realidad, lo cual en lenguaje teológico significa "la mayor realización posible del reino de Dios". Y por ello, Ellacuría define la teología formalmente como "momento ideológico de una praxis eclesial c histórica"32.

\subsection{El quehacer teológico desde los pobres}

Esta finalidad —el para de la teología- es ya conocida, pero hay que añadir algo que Ellacuría también desarrolló en profundidad: el desde, es decir, el lugar del quehacer teológico. Determinar este lugar es de suma importancia, pues según se elija uno u otro lugar las fuentes del conocimiento teológico darán de sí una u otra cosa. Pues bien, para Ellacuria

los pobres en América Latina son lugar teológico en cuanto constituyen la máxima y escandalosa presencia profética y apocalíptica del Dios cristiano $y$, consiguientemente, el lugar privilegiado de la praxis y de la reflexión cristiana. Esto lo vernos y lo palpamos en la realidad histórica y en los procesos que vive América Latina, y lo reconlimnamos en la lectura que desde ese lugar hacemos de la palabra de Dios y de toda la historia de la salvación 33 . 
Esto que aquí dice en lenguaje teórico lo reflexiono históricamente, y asi solía preguntarse cómo es posible, por ejemplo, que un tema tan central, histórica y teológicamente. como es la liberación, tema que incluso las dos instrucciones valicanas de 1984 y 1986 sobre la teología de la liberación 34 reconocen ahora como central también en la revelación de Dios, haya sido ignorado por siglos en la teología, incluso en la teología europea avanzada, tan cientifica y tan dotada de toda suerte de medios ${ }^{35}$. Y la respuesta es que lo que ha permitido el redescubrimiento de la liberación es el lugar en que se ha hecho la reflexión teológica. Si en América Latina se ha recuperado la liberación como algo central en la revelación de Dios y en el evangelio de Jesús, ello ha ocurrido porque es un continente pobre. $Y$ añadía polémica y dialécticamente que el "lugar propio de aparecer (de la liberación) es el de los miserables y desheredados y no el de los ricos desheredantes, quienes más bien propendían a no ver y aun a oscurecer la justicia y la necesidad de liberación"36. En forma personal solía decir, sobre todo cuando hablaba en España y en otros países del primer mundo, que "nosotros - los teólogos de la liberación- no somos más inteligentes que otros, ni tenemos más medios que otros, sino que muchas veces sucede lo contrario. Lo que pasa es que estamos en el lugar adecuado para pensar la fe cristiana: un mundo de pobres".

Digamos para terminar este apartado que Ellacuría, al hablar del lugar de la teología, distinguía entre lugares físicos, que podían ser distintos (una universidad, un seminario, una curia, las comunidades de base...), y el lugar real que tiene que ser la pobreza. Los lugares físicos aportan ventajas y desventajas para el quehacer teológico, pero todos ellos deben estar transidos de la realidad de la pobreza y en cualquiera de ellos el télogo debe estar afectado por esa realidad.

En concreto, Ellacuria apreciaba dos lugares fisicos para hacer teología: la universidad (por la posibilidad de análisis estructurales, interdisciplinaridad y rigurosidad, con el peligro de distanciamiento físico de la realidad) y las comunidades de base (por la inmediatez a la realidad de la vida y de la fe, por la calidad de su esperanza y de su compromiso martirial, con el peligro de inmediatismo), y deseaba que ambos lugares convergiesen en aportar y analizar la realidad de la pobreza. A quienes no aceptaban las comunidades como lugar para hacer teología, solía decir que las comunidades más que contenidos teológicos aportan luz para ver cualquier contenido, lo cual es más importante. $Y$ a quienes criticaban la universidad como lugar de la teología, por estar alejado de la realidad, les decía que "hacemos teología en un escritorio, pero no desde un escritorio".

\subsection{Un talante teológico integral}

Con estas determinaciones del lugar y de la finalidad de la teologia podemos caracterizar el talante del quehacer intelectual y especificamente teológico de Ellacuría, comparándolo con otros talantes y otras formas convencionales de

Digitalizado por Biblioteca "P. Florentino Idoate, S.J."

Universidad Centroamericana José Simeón Cañas 
hacer teología. Para hacerlo de lorma sencilla y grálica, podemos comparar lo que aparece en el origen del pensamiento occidenal y sus diversas expresiones presocrática. socrática y aristotélico-analíticat. con cl talante intelectual de Ellacuría.

Hacer teología con la linalidad anteriormente expuesta es, en primer lugar. expresión de la dimensión socrárica!n del quehacer inielectual, es decir. el enfrentarse directamente con la realiclad para transformarla y con sus poderes para combatirlos. Como el de Sócrates, el martirio de Ellucuría mucsira cuic haly un modo de cjercitar la inteligencia cuya finalidad es incidir directamente en la realidad, Iransformar las personas y las cstructuras realmente, de modo yuc el cambio que se busca. la liberación, no sea sólo un posible electo de la lïlosolïa y de la teología, sino que es lo directamente pretendido por ellas y lo regulador del guehacer intelectual.

En segundo lugar, hacer teología desde el lugar descrito es lambićn -itunque aquí el paralelismo sea inenos preciso- una formia de recuperar la dimensión presocrática del quehacer intelectual, por la actitud de inmediate\% con lia realidad y de apertura a la novedad de la historia. Esto significal conlrontarse teóricamente con la realidad, cuando para ello no haly todavía, por delïnición. textos en que apoyarse, sino que hay que leer en la realidad to que elli dice. los signos de los tiempos ${ }^{38}$. es decir, cuando no se pueden presuponer conceptos y tcorías previas - por venerables que sean- que sean ya adecuados y sulicienles para interpretarla.

Además, la realidad deviene lo que deviene, y no sc ajusta a lo que le prescriben manuales de cualquier signo, pero ni siquiera se ajusta a los pronósticos hechos con la mayor lucidez, como ha ocurrido prácticamente en todos los procesos concretos de liberación. Pues bien, aceptar y reconocer honradamente este hecho es también necesario y supone la actitud que heinos llamado presocrática: no podemos presuponer que ya contamos siempic con callegorías previas adecuadas para analizar una realidad cambiante, sino que hay guc huscarlas activa y creativamente.

Por último, Ellacuría insistió mucho en la dimensión analílica -arisforélica, digamos39- del quehacer teológico, en lo que mostró una capacidad excepcional. Más aún, insistió enormemente en su necesidad y siempre impulsó cl crecimiento de saberes rigurosos en la UCA, sin los cuales no se puede impulsar eficazmente ni la justicia, ni el desartollo, ni la liberación. Pcro Ellacuría también pensaba que, dejada a su inercia y sin la conjunción de las ouras dos dimensiones, la inteligencia puramente analítica no tiene por cuć humanizar a los humanos ni transformar la sociedad en la dirección correcta. como io muestra la inmensa acumulación de saberes en personas e instituciones, en el primer mundo sobre todo, que no ha servido muchas veces para la liberación, sino para la opresión. 
Podemos decir, resumiendo, que en el quehacer intelectual de Ellacurfa se pueden apreciar claramente las tres dimensiones mencionadas. La dimensión pre-socrática queda de alguna forma expresada en la inmediatez con que se enfrentó a la realidad, sobre todo a la realidad sufriente de los pueblos crucificados, y en la apertura a cambiar y buscar nuevas categorías conceptuales, sin presuponer que siempre tenía de antemano categorías adecuadas para abordar la novedad de los procesos. La dimensión aristótelica, analítica, la expresan sus análisis téricos de todo tipo, teológicos, filosóficos, polf́ticos, religiosos, y su instrumental rahneriano, zubiriano, marxiano, por lo que es más conocido por los de lejos. La dimensión socrática, por último, queda expresada en la voluntad de uransformar la realidad, cargando con ella, sin rehuir las consecuencias del enfrentamiento directo con los poderes del mundo: como Sócrates, ser acusado de corromper a los ciudadanos y de ateísmo, y ser por ello ajusticiado.

Esta forma teórica -integral y novedosa- de explicar el funcionamiento de la inteligencia tiene en Ellacurfa raíces zubirianas y marxianas, pero el redescubrimiento existencial de su dimensión ética y práxica está enraizado, pensamos, en lo más hondo de su persona ante la interpelación de los pueblos crucificados.

\section{La visión utópico-profética de la realidad}

\subsection{Necesidad actual de profecía y utopía}

Hoy en día, sobre todo en el primer mundo, ni los filóso fos ni casi los téblogos hablan de profecia y menos de utopia. Y ello no es casual porque ambas cosas dependen no ś́lo ni principalmente de talantes personales, sino de realidades objetivas. De profecía no quieren hablar, porque entonces tienen que preguntarse por los males de la realidad, denunciarlos y dejar que aflore al menos la pregunta de quién es responsable de la catástrofe mundial en que vivimos. Y tampoco se habla de utopía porque el ilimitado progreso, la ilimitada libertad —cuando no la ilimitada riqueza y el ilimitado placer- no se han hecho ni pueden hacerse, tal como se han pensado, realidad en nuestro mundo. $Y$ como el primer mundo, y especificamente Europa, piensa que es "la medida de todas las cosas" - lo que los griegos afirmaban sólo del ser humano- sentencian autoritativamente que ya no es tiempo de hablar ni de profecfa ni de utopía.

Pues bien, Ellacurfa en su último artículo teológico — verdadero testamento escrito pocos meses antes de ser asesinado- escribió precisamente sobre Utopía y profetismo desde América Latina 40 . Lo que ahora queremos recalcar es que no lo escribio porque ése fuese uno de los temas necesarios para, por así decirlo, redondear y dejar a la posteridad un sistema filosofico y teológico suyo completo y acabado. Y al escribir sobre estos temas, tampoco se redujo, como 
ocurre frecuentemente, a dialogar con lo que otros pensadores han dicho sobre profecla y utopía. Lo escribio, más bien, por humano y por cristiano, para expresar el dolor de las victimas y denunciar la pobreza, la represión y la muerte, lo escribió también para expresar esperanza y anunciar la posibilidad de vida, y lo escribió, por último, con convicción y audacia, para expresar su propia visión de lo último de la realidad. Ellacuría tuvo la audacia hasta el final de sus días de decir que hay un mal último que hay que denunciar proféticamente y que hay una esperanza última que hay que anunciar utópicamente.

Es imposible resumir ahora su largo escrito, pero citemos las palabras iniciales que iluminan, positiva y polémicamente, el lugar y el modo de abordar el tema:

Para lograr la conjunción adecuada de utopía y profecía cs menester situarse en el lugar histórico adecuado. Toda conjunción de esas dos dimensiones humanas e históricas, para ser realista y fecunda, necesita "situarse" en precisas coordenadas geo-sociales-temporales. De lo contrario desaparece el impulso insoslayable del principio de realidad, sin el que ambas son juego mental, más que forma real. Pero hay unos lugares más propicios al surgimiento de utopistas proféticos, de profetas utópicos. Se dice que en las culturas envejecidas ya no hay lugar para el profetismo y la ulopía, sino para el pragmatismo y el egósmo, para la verificación contable de los resultados, para el cálculo científico de insumos y resultados; en el mejor de los casos para la institucionalización, legalización y ritualización del espíritu que renueva todas las cosas. Sea o no inevitable esta situación, quedan, sin embargo, lugares donde la esperanza no es, sin más, la sumatoria de cálculos infinitesimales, sino el de esperar y "esperanzar" contra todo juicio dogmático, que cierra el futuro del proyecto y de la lucha. Uno de esos lugares es América Latina4l.

Como comentario a este texto queremos hacer algunas reflexiones importantes. Ante todo, que en Ellacuría la profecía no se debe comprender desde lo puramente temperamental de su persona, pues, aunque fuese duro de carácter, no odiaba a nadie como lo dijo públicamente en televisión con toda sencillez, pero tampoco la utopía, pues nada tuvo de veleidoso soñador. Profecía y utopla aparecen, más bien, como exigencias de la misma realidad, la cual -como decía Rahner- forcejea por tomar la palabra. Lo que es específico de Ellacuría es el añadido de que no en todos los lugares la realidad forcejea de la misma manera ni se expresa con los mismos clamores y esperanzas.

En cuanto al contenido, el texto afirma -y aqứ está probablemente lo más original de su visión-, que hay que ver ambas cosas en mutua referencia y en conjunción dialéctica, de modo que la una se remila y tenga que remilirse a la otra de manera precisa: tiene que haber utopía porque la profecía nos dice que hay un mal que superar, y puede haber profecía porque la utopía nos dice que 
hay la posibilidad de un bien. En este sentido, sí se puede decir que Ellacuria establece un verdadero "realismo" - cómo método sobre todo- que no tiene que ver con la simple aceplación de las posibilidades de las cosas, sino con el modo real de hacer que la realidad dé más de sf́, negando y afirmando. Por eso dice que hay que usar la profecía corno mélodo y la utopia como horizonte42, de modo que de la conjunción de ambas cosas se sepa hacia dónde hay que ir y qué es lo que hay que hacer.

Por último, el texto insiste en que, aunque se pudiera establecer téricamente la mutua referencia entre utopia y profetismo, el problema es encontrar aquel lugar en que cada una de ellas y su mutua referencia son posibles. Ese lugar, coherente con lo que hemos visto antes, es América Latina, mundo de pobres, y desde él Ellacuría denunció proféticamente los males y también la solución que nos ofrecen, y anunció utópicamente la verdadera solución.

\subsection{La profecía: estamos mal y nos ofrecen una mala solución}

Ya hemos visto el juicio de Ellacuría sobre la realidad de este mundo como pecado objetivado. A esto queremos añadir ahora dos cosas.

a) Además de la muerte de las víctimas existe el gigantesco cncubrimiento que los poderes de este mundo operan sobre ella y el autoengaño en que éstos viven, el primer mundo sobre todo. Para superar todo cllo pedía - y ofrecía- al primer mundo mirar cara a cara la verdadera realidad del mundo, que mayoritariamente es el tercer mundo.

La exterioridad del tercer mundo descubre así y denuncia la interioridad del primer mundo, algo que no se quiere mirar porque pondría en trance de locura o de conversión toda una forma de ser y de hacer43.

Y la misma idea repetía en forma de metáfora. Mirando a ese tercer mundo, el primero podrá, como en un espejo invertido, reconocerse en su realidad desfigurada, pero verdadera, a partir de lo que produce: los pueblos crucificados. $Y$ lo mismo decía usando la metáfora del coproanálisis: si se quiere saber cómo está la salud del paciente hay que hacer un análisis de heces. Pues bien, lo que aparece en ese análisis es la tragedia del tercer mundo, lo cual da la medida de la salud del primer mundo que lo produce.

Esto es bien conocido y no hay que abundar en ello, pero quisiera precisar dos cosas. La primera es que la hondura de su denuncia provenía de considerar los males de la realidad como pecado -es decir, de considerarlos en ultimidad - y no sólo como limilaciones, fracasos parciales, pasos fallidos pero necesarios para un futuro mejor etc., como pueden presentarlos filosolías e ideologías. En nuestra opinión, la fuerza principal de su denuncia provenfa de la objetividad del análisis y de la interpretación (cristiana) de esos males como realidad última ${ }^{44}$. $Y$ la segunda es que su denuncia profética se dirigía principalmente 
contra realidades objetivas y estructurales, y contra los grupos responsables de ellas, más que contra las personas concretas. Es decir, la finalidad de la denuncia consislía en desenmascarar realidades que deben ser transformadas. y lo que lo movía a ello era la defensa de las víctimas, no el insulto al adversario, aunque Ellacuría podía ser mordaz en su denuncia.

b) Pero siendo esto importante, quizás lo más específico de la profecía de Ellacuría - precisamente porque lo que más le interesaba era la solución de los males - consistra en denunciar y desenmascarar con vigor y rigor poco vistos no sólo los males de la realidad, sino las soluciones que nos proponen para alivio de esos males, soluciones que nos las presentan como atractivas, incluso ideales, y en cualquier caso como inevitables - lo cual, además, convertiría en inứtil y sinsentido cualquier denuncia profética.

En el actual ambiente de antiprofeća Ellacuría dijo en uno de sus últimos discursos las siguientes palabras, que pocos se atreverán a pronunciarlas, aunque siguen siendo válidas:

Desde mi punto de vista -y eso puede ser algo profético y paradojico a la vez-Estados Unidos está mucho peor que América Latina. Porque Estados Unidos tiene una solución, pero, en mi opinión, es una mala solución, tanto para ellos como para el mundo en general45.

Esa solución, que Ellacuría denunciaba como "la civilización del capilal", es la sociedad democrática neoliberal, que hoy nos proponen e imponen de forma avasalladora y de la que afimman que ha resuelto los problemas básicos en los países del sudeste asiático, y, además, que es el único camino viable. Sin embargo, decía Ellacuría que eso es una mala solución, porque no es universalizable, y por ello - por definición- no es solución para loda la familia humana, y eso mismo la convierte en solución inmoral, según aquello de Kant de que lo que no es universalizable no es moral.

Ellacuría insistía en que simplemente no hay recursos en el planela para que todos en él puedan llegar a vivir como Estados Unidos, o la comunidad europea o ni siquiera como los cuatro dragones asiálicos, con lo cual — si esto es así- a la solución que nos proponen le es inherente el tener que tomar la trágica decisión sobre qué pueblos van a vivir y cuáles van a morir, qué porcentạe de población dentro de los países pobres -el 40 , el 50 o el 60 por ciento- va a sobrevivir, y quién decide sobre ello, a no ser que la vida y la muerte de los seres humanos se deje a la frialdad del mercado. Y si no es posible garantizar el mínimo de vida, entonces, una vez más, de los bienes de esa sociedad supuestamente más civil y más democrática gozarán sólo unos pocos - lo cual es una contradicción- y quedará todavía más sofocada la noción misma de familia humana.

Esta mala solución es la que debe ser denunciada proféticamente y a la que Digitalizado por Biblioteca "P. Florentino Idoate, S.J." Universidad Centroamericana José Simeón Cañas 
hay que oponer una verdadera solución, que hay que buscarla, pensaba Ellazuria, por rumbos muy distintos y aun contrarios.

\subsection{La utopía: una civilización de la pobreza}

Incluso en el caso de que la solución que nos quieren imponer fuese viable desde un punto de vista económico, Ellacuría no la juzgaba deseable. Sobre cuál fuese la verdadera solución solía decir que su conceptualización teórica era fácil, pero que su puesta en práctica era sumamente diffcil, realmente "utópica" - lo que no ha lugar. Esa verdadera solución suponía no sólo reformas, sino "conversión y transformación, ... otra inspiración contraria a la actual, ... cambio de inentalidad y cambio de rumbo historico" 46 . A esa solución la llam6 "civilización del trabajo", y, en formulación más original, "civilización de la pobreza".

A mi entender, esta última formulación ${ }^{47}$, y lo que está tras ella, es creación original de Ellacuría, que la trabajó teóricamente durante varios años 48 , y a la que le dio gran importancia porque pensaba que era la única forma de hacer real en nuestro mundo "la civilización del trabajo" y de historizar "la civilización del amor" - a la que, por cierto, nos llaman los papas.

Que yo recuerde, sobre ello escribió por primera vez en 1982 en un artículo sobre el paro para la revista Concilium 49 . Después, en 1983, abordó el tema a propósito de lo que debía ser la misión de la Compañía de Jesús, que iba a celebrar ese año su congregación generalso. Por último, volvió sobre ello en 1989 en el arículo ya citado "Utopía y profetismo".

Sobre esta civilización de la pobreza escribió programáticamente en 1982:

... una civilización de la pobreza, donde la pobreza ya no sería la privación de lo necesario y fundamental debida a la acción histórica de grupos o clases sociales y de naciones o conjunto de naciones, sino un eslado universal de cosas en que esté garantizada la satisfacción de las necesidades fundamentales, la libertad de las opciones personales y un ámbito de creatividad personal y comunitaria que permita la aparición de nuevas formas de vida y cultura, nuevas relaciones con la naturaleza, con los demás hombres, consigo mismo y con Diossi.

Estas palabras son utópicas y no hay en ellas mucho análisis. Lo que vienen a decir con fuerza es que la actual civilización no lo es, pues no ha propiciado para todos los hombres y mujeres los bienes que se mencionan, lo cual es un ejemplo de cómo el lugar de la utopla es el mismo que el de la profecía. Sin embargo, en el mismo artículo apunta ya a dos cosas importantes. La primera es que la actual civilización no sólo no lo es, sino que la causa de ello está en ser una civilización de la riqueza. En términos cristianos, Ellacuría recalca que vivimos en un mundo de pecado52, lo cual "se agrava más porque el primer mundo 
se dice cristiano, fruto de la civilización cristiana, misionero del evangelio que llevó al tercer mundo como un ingrediente más de la colonizacion" 53 . Y la segunda es que el problema es más profundo de lo que parece pues se trata de que "se cree no sólo un orden económico mundial nuevo ... sino una civilización nueva" 54.

En el artículo de 1983 recalca que esa civilización es tanto una necesidad histórica -dada la correlación mundial recursos-población-, como una posibilidad para que crezca el espíritu, y desenmascara el presupuesto generalmente aceptado de que la civilización occidental —aunque en otras cosas haya podido fallar- al menos no habría fallado en el cultivo del espíritu:

Esa pobreza es la que realmente da espacio al espíritu, que ya no se verá ahogado por el ansia de tener más que el otro, por el ansia concupiscente de tener toda suerte de superfluidades, cuando a la mayor parte de la humanidad le falta lo necesario. Podrá entonces florecer el espíritu, la inmensa riqueza espiritual y humana de los pobres y los pueblos del tercer mundo, hoy ahogada por la miseria y por la imposición de modelos culturales más desarrollados en algunos aspectos, pero no por eso más plenamente humanosss.

En el artículo de 1989 vuelve a precisar la oposición dialéctica a la civilización de la riqueza y los dinamismos antagónicos de ambas:

La civilización de la pobreza ... fundada en un humanismo materialista, transformado por la luz y la inspiración cristiana, rechaza la acumulación del capical como motor de la historia y la posesión-disfrute de la riqueza como principio de humanización, y hace de la satisfacción universal de las necesidades básicas el principio del desarrollo y del acrecentamiento de la solidaridad compartida el fundamento de la humanización.

La civilización de la pobreza se denomina así por contraposición a la civilización de la riqueza y no porque pretenda la pauperización universal como ideal de vida... Lo que aquó se quiere subrayar es la relación dialéctica riqueza-pobreza y no la pobreza en sí misma. En un mundo configurado pecaminosamente por el dinamismo capital-riqueza es menester suscitar un dinamismo diferente que lo supere salvfficamentes6.

Estas palabras no necesitan comentario, pero sf es bueno insistir en que lo que aquí formula Ellacuría como utopía no es sólo una posibilidad de vida para las mayorías, sino la posibilidad de civilización, es decir, de un modo de vida realmente humano y fraterno; y por ello estas palabras son también una denuncia profética a la civilización de la riqueza, la cual no sólo no genera vida para todos, sino que no civiliza a los seres humanos, no los humaniza.

A la dimensión de civilización, no sólo de producción y distribución economica, Ellacuría fue cada vez más sensible, y por ello se interesó cada vez más en todo lo que fuese manifestación del espiritu. Por poner un ejemplo importan- 
te, en la descripción de los pobres insistió en su realidad material de carencia, en su realidad histórica de haber sido empobrecidos, en su potencial para adquirir conciencia y organizarse políticamente, pero a todo ello añadí la necesidad y posiblidad de estar imbuidos de y producir espíritu, de modo que una de sus formulaciones utópicas más profundas fue la de "pobres con espiritu"57.

Esta utopía la pensó teóricamente, pero también ajustado a las necesidades y posibilidades de la realidad salvadoreña. De acuerdo al realismo que antes hemos mencionado, y que constituyó en sus últimos años una gran preocupación suya, esto es lo que dijo en su discurso de Barcelona:

Queda otro paso también lundamental y es el de crear mudelos económi$\cos$, polf́ticos y culturales que hagan posible una civilización del trabajo como sustitutiva de una civilización del capital. Y es aqur donde los intelectuales de todo tipo, esto es, los téricos críticos de la realidad, tienen un reto y una tarea impostergables. No basta con la crítica y la desırucción, sino que se precisa una construcción que sirva de alternativa real58.

Por otro lado, Ellacuría elaboró la utopía según lo que la realidad salvadoreña iba dando de sí, y así vio gérmenes -imperlectos y muchas veces fallidos, ciertamente- de la civilización de la pobreza en varios logros del pueblo y de la Iglesia salvadoreña: organización popular más que partidos políticos tradicionales, ensayos de economía popular y comunitaria, construcción de una Iglesia de los pobres. Y vio también cómo se fueron creando valores más afines a la civilización de la pobreza que a la de la riqueza, que en formulación nuestra pudieran describirse así: el espiritu de comunidad versus el individualismo aislacionista, que fácilmente degenera en egoismo; la celebración versus la diversión irresponsable, que degenera en alienación; la aperlura versus el etnocentrismo cruel, que degenera en desentendimiento del sufrimiento de los otros; la creatividad versus la imitación servil, que fácilmente degenera en pérdida de identidad propia; el compromiso versus la mera tolerancia, que degenera en indiferencia; la fe versus el burdo positivismo y pragmatismo, que degenera en sinsentido de la vida...

\subsection{La esperanza que no muere}

Decíamos antes que para Ellacuría es mejor no tener solución que tener una mala solución. Pero el mismo Ellacuŕa terminaba con esta esperanza utópica de solución y con una fundamentación más utópica todavía:

Toda esta sangre martirial derramada en El Salvador y en toda América Latina, lejos de mover al desánimo y a la desesperanza, infunde nuevo espíritu de lucha y nueva esperanza en nuestro pueblo. En este sentido, si no somos un "nuevo mundo" ni un "nuevo continente", si somos, claramente, y de una manera verificable $-y$ no precisamente por la gente de fuera - un continente de esperanza, lo cual es un síntoma sumamente interesante de una 
futura sociedad frente a otros continentes que no tienen esperanza y que lo único que tienen es miedo59.

Ellacuría se opuso, pues, frontalmente no sólo a la civilización de la riqueza, sino a sus acompañantes históricos actuales, la desesperanza, el miedo, el sentido de frustración y de inevitabilidad, es decir, se opuso a una cultura sin profecía y sin utopía, y afirmó -y lo vivió- que por la alternativa profético-utópica merece la pena vivir y morir.

Nada de esto es fácil en la práctica, pues ese tipo de vida, más humano y más cristiano, no interesa al sistema, y por ello suele ser descalificado teóricamente, y, cuando toma cuerpo, suele ser perseguido históricamente. Pero aun sicndo difícil, es posible, es necesario y es bueno. Asf lo entienden no los que en la abundancia ya dan la vida por supuesto, pero lo entienden sf aquellos que lo que no dan por supuesto es precisamente la vida, vida con un mínimo de posibilidades y de dignidad. Estos entienden de qué se trata y qué está en juego en una civilización de la pobreza, y entienden que muchos seres humanos hayan entregado generosamente su vida por esa utopía.

Para tcrminar la presentación del ser humano que fue Ellacurla, su esperanza y su compromiso, vamos a reproducir unas palabras centrales de su discurso de Barcelona:

Lo que queda por hacer es mucho. Sólo utópica y esperanzadamente uno puede creer y tener ánimos para intentar con todos los pobres y oprimidos del mundo revertir la historia, subvertirla y lanzarla en otra dirección... Esta civilización está gravemente enferna y para evitar un desenlace fatŕdico y fatal, es necesario intentar cambiarla desde dentro de sf misma. Ayudar profética y utópicamente a alimentar y provocar una conciencia colectiva de cambios sustanciales es ya de por sí un primer gran paso60.

Notas:

I. La apreciación del pensamiento de Aristóteles $\rightarrow$ de la música de Beethoven- prácticamente no dependen ya del conocimiento de sus persones, pero en el caso de otros pensadores y personajes las cosas no son asl. sobre todo cuando se dan las siguientes circunstancias: cercanfa en el tiempo, conocimiento público y suficientemente masivo de la persona y de su incidencia, explícitamente pretendida, en la saciedad, y más si a esto se añade una muerte martirial. Así, por poner dos ejemplos, para comprender la teología de Dielrich Bonhoeffer o las homillas de Monseñor Romero es muy importante conocer su vida personal y su muerte en ambos casos martirial.

2. "Liberación". Revista Latinoamericana de Teología 30 (1993) 217. Ellacurfa se refiere en este lexto al pecado personal, pero lo que dice se puede aplicar a toda accion humana. 
3. Sub specie contrarii esto se esclarece al ver cómo citan y tratan de interpretar algunos al pensador Ellacuría con independencia de su persona. Suele ocurril, entonces. que aquéllos captan. $u$ pueden captar, el contenido formal de los conceptos utilizidos por él, pero no parecen captar suficientemente el peso histórico de esos contenidos.

4. A. González. "Aproximación a la obra filosofica de Ignacio Ellacuría". ECA 505506 (1990) 980. Esto mismo puede decirse y con mayor razón de su tcología, ya que lo teológico alcanzó las raíces más hondas. por cristianas. de su persona.

5. La verdad es que la derecha sigue rechazando o ignorando a Ellacuría, La inanipulación, burda o sutil, quizás proviene ahora más bien de la izquicrda. Unos, fuera de El Salvador, Jo quisieran gánar para ideales y aun métodos violentos que él condenó, y otros, en El Salvador, recuerdan ahora su tarea mediadora y negociadora para justificar la relativización de todo lo que sea profecía y utopía en favor del realismo político. realismo que Ellacuría propició ciertumente. pero no separado de la profecía y la utopía.

6. Ellacurla tuvo grandes cualidades. pero también limitaciones, sobre todo de tipo caracteriológico y temperamental, lo cual él misıno rcconocía. Lo que quisiera añadir es que Ellacura, al pensar la realidad y actuar sobre ella, lo hizo con csas limitaciones, pero no por causa de ellas. En otras palabras, sus limitaciones no fueron principio, en el sentido de lo que "principia". pone en movimiento y da dirección a una vida. Ese principio, aunque estuviese acompañado y de alguna forma afectado por sus limitaciones, hay que buscarlo en lo positivo de su persona, tal como lo vamos a analizar.

7. Por decirlo de forma grálica, no me imagino yo a Ellacuría cambiando radicalmente su modo de ser, de pensar y de actuar, aunque por alguna razón hipotélica hubiesc tenido que abandonar la Compañía de Jesús o la Iglesia.

8. Este concepto de misericordia lo hemos elaborado en El principio misericordia. Bajar de la cruz a los pueblos crucificados (Santander 1992. San Salvador 1993). Si lo menciono aquí es para dejar constancia de que mucho de lo que escribo en ese libro proviene de observar a personas como Ellacurfa y Monseñor Romero. Y por ello, aunque no sea habitual, repito en este escrito como subtitulo lo que me parece a mí que mejor nos introduce en la persona de Ellacuría: bajar de la cruz al pucblo crucificado.

9. X. Gorostiaga, "La mediación de los cambios sociales y los cambios internacionales", en Cambio social y pensamiento cristiano en América Latina , J. Comblin, J. I. González Faus, J. Sobrino (eds.) (1993) 131.

10. "El desaffo de las mayorfas populares", ECA 493-494 (1989)1076.

11. No es nada infrecuente que el tipo de personas mencionadas no estén interesadas en confrontarse con la realidad tal cual es para no quedar expuestas, indefensamente. a los cuestionamientos y exigencias de esa realidad, a lo cual se añade que algunos intelectuales, sobre todo- suelen pensar que el acercamiento a la realidad concreta nada importante puede aportar a su comprensión teórica de ella.

12. "Discernir el signo de los tiempos", Diakonfa 17 (1981) 58. En mi opinión. en este párrafo Ellacuría está usando el concepto "signo" (de los tiempos) no solo en su acepción histórico-pastoral como aquello que caracleriza una epoca ( cfr. GS 4), sino también en su acepción histórico-teologal como lugar de presencia de Dios o de sus planes (cfr. GS 11). Con esto se quiere afirmar, teológicamente, que el mismo Dios

Digitalizado por Biblioteca "P. Florentino Idoate, S.J."

Universidad Centroamericana José Simeón Cañas 
está presente en el pueblo crucificado, y al hacer uso de esa radical teologización se afirma también la ultimidad de la tragedia histórica.

13. "Función liberadora de la filosofía", ECA 435-436 (1985) 50. Ellaciıría está haciendo alusión a la conocida pregunta de Heidegger en Was ist Metaphysik?

14. "Quinto centenario de America Latina. ¿Descubrimento o encubrimiento?". Revista Latinoamericana de Teologia 21 (1990) 278.

15. "A Dios Padre le salieron y/o le resultaron muchos hijos pobres... Este es un hecho primario y masivo, que no puede pasar por alto quien quiera hablar de Dios", "Pobres", en Conceptos fundamentales de Pastoral, C. Flonistán y J. J. Tamayo (eds.) (Madrid 1983) 790.

16. Ellacurfa fue en muy buena medida el inspirador de la sección de la cuarta carta pastoral de Monseñor Romero que trata sobre la idolatrfa, cfr. "Misión de la Iglesia en medio de la crisis del pals", en La voz de los sin voz, J. Sobrino, I. Martín-Baró, R. Cardenal (eds.) (San Salvador 1980) 145-149.

17. "Aporte de la teología de la liberación a las religiones abrahámicas en la superación del individualismo y del positivismo", Revista Latinoamericana de Teologla 10 (1987) 9.

18. En "Liberación" 697-703 elabora un concepto sistemático y abarcador de liberación que tiene en cuenta lo personal y lo social, lo histórico y lo teologal.

19. Qué hubiese hecho Ellacuría si hubiese sido, por ejemplo, secretario general de un sindicato o superior de una congregación religiosa o pámoco u obispo, no lo sabemos, por supuesto, pero creo que su actilud personal fundamental hubiese sido la misma: relacionar cualquiera de esas realidades -sindicatos, congregación religiosa, parroquia, diócesis - con la justicia y la liberación, y ponerlas a su servicio.

20. Dicho esto en forma sencilla, cuando en los años setenta era formador de jóvenes jesuitas, inquietos por el deseo de participar en los procesos de liberación y desanimados por los largos años de estudio que parecían impedirlo, Ellacuría -a modo de consuelo y exigencia - solía repetirles que el saber era imprescindible para la liberación y que lo que tenían que hacer era estudiar de la manera adecuada, desarrollando "una pasión revolucionaria por el estudio".

21. Por eso solfa insistir en que el instnumento -y el arma, si se quiere- específico de la universidad para influir en la sociedad era la palabra racional. En ello vela también afinidad con la lgiesia, lo cual quedó esclarecido muy importaniemente por la actuación de Monseñor Romero a través de su palabra pastoral.

22. "Discurso de graduación en la Universidad de Santa Clara, 12 de junio de 1982", Carta a las Iglesias 22 (1982) 12.

23. "Universidad y política", en ECA 381-382 (1980) 813.

24. Ibid. ,816.

25. "Discurso...", 11.13.

26. La voz de los sin voz..., 453.

27. "Discurso...", 14.

28. Se trata del coloquio que san Ignacio pone al final de la meditación del pecado, cuyo texto dice: "Imaginando a Cristo nuestro Señor delante y puesto en cruz, hacer un coloquio, cómo de Criador es venido a hacerse hombre, y de vida etema a muerte temporal, $y$ as! a morir por mis pecados. Otro tanto mirando a $\mathrm{mf}$ mismo lo que he hecho por Cristo, lo que hago por Cristo, Jo que debo hacer por Cristo, y así viendole tal, y así colgado en la cruz, discurrir por lo que se ofreciere", Ejercicios Espiri- 
ruales n. 53.

29. "Lis iglesias latinoamericanas interpelan a la Iglesia de España", Sal Terrae 3 (1982) 230.

30. "Hacia una fundamentación filos6lica del método teologico latinoamericano", ECA $322-323$ (1975) 419.

31. Ibid.

32. "La tcología como momento ideológico de la praxis eclesial". Estudios Eclesiásticos 207 (1978) 457-476.

33. Conversión de la Iglesia al reino de Dios (Santander-San Salvador 1985) 163.

34. Dice la Libertatis numius: "EL Evangelio de Jesucristo es un mensaje de libertad y una iuerza de liberación" (Introducción). "La aspiración a la liberacion... toca un tema fundamental del Antiguo y del Nuevo Testamento" (III, 4). Y la Liberiatis conscientia dice que el Evangelio "es. por su misma naturaleza, mensaje de liberad y de liberación" (Introducciónl).

35. "Lihcracion". 213s.

36. "Estudio tcológico-pastoral de la Instruccion sobre algunos aspectos de la reología de la liberación". Revista Latinoamericana de Teología 2 (1984) 150.

37. No nos referimos aquí al método mayćutico. sino al talante de su modo de pensar. desenmascarador y práxico, para transformar la polis.

38. Esto se aplica todavía con más claridad a las primeras teologías del Antiguo y dej Nucvo Testamento. Sus aulores, fuesen quienes fuesen. estaban confrontados con la realidad y no podian, por definición, remitirse a tradiciones o a teologías previas parn interpretarla.

39. Ellacuría recalcaba las dimensiones que hemos Ilamado socráticas y presocráticas del quehacer intelectual sobre todo en el primer mundo. pucs en él se suelen ignorar con gran frecuencia. Aqui entre nosotros, con penurias culturales y cientílicas de todo lipo. recalcaba muy especialmente la dimensión analítica para acumular el mejor y mayor número de saberes rigurosos. pucstos siempre al servicio de la liberación.

40. Revista Latinoamericana de Teología 17 (1989) 141-184.

41. Ibid., $141 \mathrm{~s}$.

42. Cfr. ibid., 142.

43. "El reino de Dios y el paro en cl tercer mundo". Concilium 180 (1982) 593.

44. En sus apariciones en television, sobre todo en los últimos años, comunicaba todo csto con gran vigor y causaba un gran impaclo. Recucrdo que una mujer me dijo después de verjo en televisión: "Desde que mataron a Monseñor Romero nadie ha hablado como cl padre Ellacuria".

45. "Quinto centenario de América Latina. ¿Descubrimiento o encubrimiento?". Revista Latimoamericana de Teología 21 (1990) 277.

46. "El reino de Dios...". 591.

47. La lormulación es fuerte y vigorosa. pero que yo recucrde Ellacuría nunca la suavizó. Todavía en vida de êl, don Pedro Casaldáliga la recogió de la siguiente manera. "A lo 'civilizacion del amor' debería añadírsele aquello que con expresión feliz designo el télogo jesuita. español, vasco, salvadoreño. Ellacuría. como la "civilización de la pobreza"”. " A los quinientos años: 'descolonizar y desevangelizar'”, Revista Latinoumericna de Téología 16 (1989) 118 . Más recientemente. don Pedro ha hablaJo de la civilización de la "pobreza solidaria". Y si se me permite una anécdola 
personal, en enero de 1990 , hablé en televisión española sobre la civilización de la "austeridad compartida". y comenté que si yo formulara la utopla en las palabras de Ellacuria los televidentes me tirarian piedras.

48. Recuerdo que al principio hablaba de "culura de la pobreza", pero alguien le disuadió de ello por las connotaciones peyorativas del término en la antropología cultural. Valga este recordatorio como expresión del interés que Ellacurfa puso en el tema.

49. "El reino de Dios y el paro en el tercer mundo", Concilium 180 (1982) 588-596. Recuerdo, por cierto, su enfado inicial con el en[oque del número monográfico, pues estaba pensado muy desde el primer mundo y estaba muy dirigido hacia ese mundo.

50. "Misión actual de la Compaña de Jesús". Revista Larinoamericana de Teología 29 (1993) 115-126.

51. "El reino de Dios ...", 595.

52. Ibid. ,590s.

53. Ibid. ,591.

54. Jbid., 592.

55. "Misión aclual ...", 119s.

56. "Utopía...", I70s.

57. "Las bienaventuranzas, carta fundacional de la Iglesia de los pobres", "Los pobres, 'lugar teológico', en América latina", en Conversión de la Iglesia al reino de Dios, $129-151,153-178$.

58. "El desafío ...". 1078.

59. "Quinto centenario...", $281 \mathrm{~s}$.

60. "El desaff́o ...", 1078. 